\title{
Identification of a putative molecular regulator of cork cambium
}

\author{
Andreia Miguel $^{1 *}$, Pinto C Ricardo ${ }^{1}$, Brian Jones ${ }^{2}$, Célia Miguel $^{1}$ \\ From IUFRO Tree Biotechnology Conference 2011: From Genomes to Integration and Delivery \\ Arraial d'Ajuda, Bahia, Brazil. 26 June - 2 July 2011
}

\section{Background}

Cork oak (Quercus suber) is a long-living species of the Fagaceae family that highly contributes for the economy of several countries such as Portugal. It is the only plant species with a phellogen capable of a sustainable production of cork with properties suited for industry applications. Phellogen, or cork cambium, usually initiates in the subepidermis and differentiates during the first year of growth [1]. Its meristematic activity gives rise to phellem (cork) cells to the outside and to phelloderm to the inside.

It is likely that genes involved in the regulation of other plant meristems such as shoot apical meristem and vascular cambium are also involved in the regulation of phellogen. Based on its role in other meristems, and on specific expression patterns in poplar stems, we hypothesize that SHORT-ROOT (SHR), a transcription factor from the GRAS family, may be involved in the regulation of phellogen. This gene has been well described in the Arabidopsis root where it plays a key role in the radial patterning and in regulating the specification of the root stem cell niche [2-4]. Recently, its involvement in the root vascular system to control patterning processes [5] and in the control of proliferative cell division in developing leaves [6] has also been reported. In this work we report the cloning of $S H R$ from cork oak transcriptome and the characterization of SHR expression patterns in the stem with the aim of investigating its putative function in the phellogen.

\section{Materials and methods}

Through a search in public databases we have retrieved putative orthologs of ArabidopsisSHR gene from species

\footnotetext{
* Correspondence: andreiamiguel@itqb.unl.pt

${ }^{1}$ Instituto de Tecnologia Química e Biológica (ITQB)-UNL; Instituto de Biologia Experimental e Tecnológica (IBET), Av. da República, EAN, 2780-157 Oeiras, Portugal
}

Full list of author information is available at the end of the article with a sequenced genome including Populus trichocarpa, Vitis vinifera and Medicago truncatula. Based on multiple alignments at the cDNAand deduced aminoacid sequence levels, we have designed degenerate primers in order to clone and characterize SHR from cork oak transcriptome. The amplified PCRfragment was inserted into pCR2.1 (Invitrogen) and sequenced to determine the percent identity to known $S H R$ gene sequences.

To analyze $S H R$ expression patterns poplar is being used as a model tree species. Transgenic poplar plants carrying the SHR promoter fused to the GUS reporter gene have been previously generated. Stem sections collected from 1-2 year-old transgenic plants have been subject to the histochemical GUS assay and embedded in Technovit 7100 resin for detailed analysis of gene expression localization under the microscope.

Characterization of SHR transcript abundance in cork oak developing stems taking into account different developmental stages and collection seasons has also been performed.Transcript abundance was analysed in stem tissues from the first to the third year of growth collected between January and October from a cork oak tree in order to cover periods of active growth and dormancy. Reproduction cork was collected in July which is the period during which the debarking process is performed from cork producer trees. RNA was extracted according to a protocol described by Reid et al. (2006) and cDNA was successfully synthesized using the Transcriptor High Fidelity cDNA Synthesis Kit (Roche). Quantitative RT-PCRwas performed with LightCycler LC480 (Roche).

\section{Results}

While Arabidopsis has one $S H R$ gene sequence in its genome, at least two additional SHR-like sequences are present in the poplar genome. Also, more than one 
SHR-like sequence seems to be present in the cork oak transcriptome and, at the moment, one of those sequences, QsSHR1, consisting of 1455bp and showing strong homology to the Arabidopsis SHR gene, was identified, and cloned. This putative SHR-like gene from cork oak was found to be expressed in stems at different developmental stages as well as in reproduction cork. Furthermore, evidence of specific expression of one of the poplar SHR-like sequences has been found in the phellogen and lenticels of stems from transgenic poplar carrying a promoter fusion to the GUS reporter gene.

\section{Conclusions}

SHR-like genes may be involved in even more developmental processes than previously thought. It seems plausible that in woody species such as poplar and cork oak, additional copies of SHR may have evolved to acquire new functions. We expect that these results, as well as results from further ongoing studies, will contribute to elucidate the putative involvement of $S H R$ in the regulation of phellogen. Additionally, these studies may provide tools to be used in future strategies aiming at the improvement of cork production from cork oak.

\section{Acknowledgements}

Financial support provided by FCT through project PTDC/AGR-GPL/098369/ 2008 and grant SFRH/BD/44474/2008.

\section{Author details}

Instituto de Tecnologia Química e Biológica (ITQB)-UNL; Instituto de Biologia Experimental e Tecnológica (IBET), Av. da República, EAN, 2780-157 Oeiras, Portugal. ${ }^{2}$ A20 John Woolley Building, 2006 University of Sydney Australia / UPSC, Sweden.

Published: 13 September 2011

\section{References}

1. Graça J, Pereira H: The Periderm Development in Quercus suber. IAWA Journal 2004, 25(3):325-335.

2. Benfey PN, et al: Root development in Arabidopsis: four mutants with dramatically altered root morphogenesis. Development 1993, 119:57-70.

3. Helariutta $Y$, et al: The SHORT-ROOT Gene Controls Radial Patterning of the Arabidopsis Root through Radial Signalling. Cell 2000, 101(5):555-567.

4. Nakajima K, et al: Intercellular movement of the putative transcription factor SHR in root patterning. Nature 2001, 413:307-311.

5. Yu N, Lee SA, et al: Characterization of SHORT-ROOT Function in the Arabidopsis Root Vascular System. Mol Cells 2010, 30:113-119.

6. Dhondt S, Coppens F, et al: SHORT- ROOT and SCARECROW Regulate Leaf Growth in Arabidopsis by Stimulating S-Phase Progression of the Cell Cycle. Plant Physiology 2010, 154:1183-1195.

doi:10.1186/1753-6561-5-S7-P70

Cite this article as: Miguel et al:: Identification of a putative molecular regulator of cork cambium. BMC Proceedings 2011 5(Suppl 7):P70.

\section{Submit your next manuscript to BioMed Central} and take full advantage of:

- Convenient online submission

- Thorough peer review

- No space constraints or color figure charges

- Immediate publication on acceptance

- Inclusion in PubMed, CAS, Scopus and Google Scholar

- Research which is freely available for redistribution

Submit your manuscript at www.biomedcentral.com/submit 